\title{
Maternal mortality at Nnamdi Azikiwe University Teaching Hospital, Southeast Nigeria: a I0-year review (2003-20I2)
}

This article was published in the following Dove Press journal:

International Journal of Women's Health

22 July 2013

Number of times this article has been viewed

\section{NJ Obiechina \\ VE Okolie \\ ZC Okechukwu \\ CF Oguejiofor \\ Ol Udegbunam \\ LSA Nwajiaku \\ C Ogbuokiri \\ R Egeonu}

Department of Obstetrics and Gynaecology, Nnamdi Azikiwe University Teaching Hospital, Nnewi, Nigeria
Correspondence: Vitus Okolie Ezike Department of Obstetrics and Gynaecology, Nnamdi Azikiwe University Teaching Hospital, PMB 5025 Nnewi, Anambra State, Nigeria

Email vitusokolie@yahoo.com
Background: Maternal mortality is high the world over, especially in sub-Saharan Africa, including Nigeria. Nigeria has consistently demonstrated one of the most abysmally poor reproductive health indices in the world, maternal mortality inclusive. This is a sad reminder that, unless things are better organized, Southeast Nigeria, which Nnamdi Azikiwe University Teaching Hospital (NAUTH) represents, may not join other parts of the world in attaining Millennium Development Goal 5 to improve maternal health in 2015.

Objectives: This study was conducted to assess NAUTH'S progress in achieving a 75\% reduction in the maternal mortality ratio (MMR) and to identify the major causes of maternal mortality.

Materials and methods: This was a 10-year retrospective study, conducted between January 1, 2003 and December 31, 2012 at Nnamdi Azikiwe University Teaching Hospital, Nnewi, Southeast Nigeria.

Results: During the study period, there were 8,022 live births and 103 maternal deaths, giving an MMR of 1,284/100,000 live births. The MMR was 1,709 in 2003, reducing to 1,115 in 2012. This is to say that there was a $24.86 \%$ reduction over 10 years, hence, in 15 years, the reduction should be $37 \%$. This extrapolated reduction over 15 years is about $38 \%$ less than the target of $75 \%$ reduction. The major direct causes of maternal mortality in this study were: pre-eclampsia/eclampsia $(27 \%)$, hemorrhage $(22 \%)$, and sepsis $(12 \%)$. The indirect causes were: anemia, anesthesia, and HIV encephalopathy. Most of the maternal deaths occurred in unbooked patients (98\%) and within the first 48 hours of admission (76\%).

Conclusion: MMRs in NAUTH are still very high and the rate of reduction is very slow. At this rate, it will take this health facility 30 years, instead of 15 years, to achieve a $75 \%$ reduction in maternal mortality.

Keywords: maternal mortality, MDG-5, 2015, achievability, causes, NAUTH, Southeast Nigeria

\section{Introduction}

Pregnancy and childbirth are physiological events that should bring joy to the family and society at large, but sometimes it turns out to be a source of sorrow. Globally, there is an unacceptably high maternal mortality; the maternal mortality ratio (MMR) in sub-Saharan Africa is among the highest in the world, at 1,000/100,000 live births. ${ }^{1}$

Maternal mortality is a major reproductive health index and could indeed be considered to be a measure of the socioeconomic development of any nation. Nigeria has progressively demonstrated one of the most abysmally poor reproductive health indices in the world. Nigeria constitutes less than $2 \%$ of the world population but contributed $10 \%$ of the world's maternal deaths. ${ }^{2}$ Maternal mortality only tells part 
of the story: for every woman that dies as a result of complications of pregnancy and childbirth, between 20 and 30 women will develop short- and long-term disabilities such as obstetric fistula, ruptured uterus, or pelvic inflammatory diseases. This is a sad reminder that, unless things are better organized, Millennium Development Goal (MDG)-5, to improve maternal health, will not be achieved by 2015 in Southeast Nigeria.

Maternal mortality is considerably influenced by the socioeconomic and political context of a health care system and the cultural and biological realities of women seeking care. This complex interplay may result in the women delaying seeking care, and delays for women to receive care during pregnancy and delivery.

As a result of high MMRs, the world's attention was drawn some decades ago to the thousands of deaths and millions of serious complications that occur every year in association with pregnancy and delivery, resulting in a conference held in Nairobi, Kenya, in February 1987. Termed Safe Motherhood Initiative, the target was to reduce maternal mortality by half by the year 2000. This target was to be achieved through provision of widely available and affordable family planning services, easily accessible antenatal care services, facilities for safe and clean deliveries, and emergency obstetric care services. This target was not achieved by the year 2000. In September 2000, 147 world leaders met to articulate the problems of the world, especially those of developing countries, and this conference resulted in eight MDGs. MDG-5 is to improve maternal health, with a target of reducing maternal death by three-quarters (75\%) by 2015 . To achieve this, there must be a $5 \%$ reduction in maternal deaths per year over this 15-year period.

This study was conducted to assess the progress in achieving this $75 \%$ reduction in maternal mortality in a tertiary health institution in Southeast Nigeria and to identify the major causes of maternal death.

\section{Materials and methods}

File numbers of all the pregnant women that died between January 1, 2003 and December 31, 2012, during pregnancy, delivery, or within 42 days of termination of pregnancy, irrespective of gestational age or site of the pregnancy but not due to accidental or incidental causes, were collected from the labor, antenatal, and postnatal wards, intensive care unit, and operative unit of Nnamdi Azikiwe University Teaching Hospital (NAUTH), Nnewi, Southeast Nigeria. The case files of the patients were retrieved from the records department of the hospital. The following data were collected from each of the files: age; booking status (whether they received antenatal care services or not); the primary cause of death; and the number of hours the patient stayed in admission before the death occurred. The total number of maternal deaths, along with the total number of live births in each year, was collected, from which the total number of maternal deaths per 100,000 live births was calculated. Finally, the total number of maternal deaths, along with the total number of live births, during the 10 years of the study was calculated, from which the final maternal deaths per 100,000 live births (the MMR) was calculated. The categorical data were collected and represented in percentages. The data was analyzed using SPSS statistical software (v 16; IBM Corporation, Armonk, NY, USA).

\section{Results}

During the study period (2003-2012), there were a total of 8,022 live births and 103 maternal deaths, giving an MMR of 1,284/100,000 live births. Table 1 shows the distribution of maternal mortality over the 10-year period of the study: maternity mortality was over 1,000 per 100,000 live births except in 2006 (808), 2009 (749), and 2010 (691).

The causes of maternal mortality are shown in Figures 1-3. Direct and indirect causes of maternal death contributed $74.75 \%$ and $23.3 \%$, respectively, while unidentified causes constituted $1.94 \%$ of maternal deaths. The common direct causes of maternal death were pre-eclampsia, hemorrhage, sepsis, and ruptured uterus. Other direct causes of maternal death, although less common, were unsafe abortion and obstructed labor. Anemia, anesthesia, and HIV encephalopathy were the major indirect causes of maternal death.

Out of 103 maternal deaths recorded in this study, $101(98.06 \%)$ were unbooked patients, while only two (1.94\%) were booked. Seventy-eight (75.73\%) mortalities occurred within the first 48 hours of admission, while 25 (24.27\%) occurred after 48 hours of admission.

\section{Discussion}

The MMR of 1,284/100,000 live births in this study is high; it is higher than that reported in Ibadan $(309)^{3}$ or Lagos (852), ${ }^{4}$ and almost the same as that reported in Jos $(1,260) .{ }^{5}$ It is also higher than those reported in other developing countries like South Africa (340), Uganda (344), Tanzania (308), Namibia (300), and Botswana (480), and incomparably higher than what is obtainable in developed countries. ${ }^{6-8}$ This MMR is, however, lower than those reported in Port-Harcourt $(2,735)^{9}$ and Sokoto $(2,138) .{ }^{10}$ It is almost the same as that reported in NAUTH in 2007 (1,282). ${ }^{11}$ This shows that the steps that 
Table I The maternal mortality ratio (MMR)

\begin{tabular}{|c|c|c|c|c|c|c|c|c|c|c|c|}
\hline Year & 2003 & 2004 & 2005 & 2006 & 2007 & 2008 & 2009 & 2010 & 2011 & 2012 & Total \\
\hline Live births, $\mathrm{n}$ & 351 & 382 & 433 & 619 & 731 & 802 & 935 & 1,013 & 1,198 & 1,558 & 8,022 \\
\hline Deaths, $\mathrm{n}$ & 6 & 6 & 8 & 5 & 12 & 9 & 7 & 7 & 25 & 18 & 103 \\
\hline MMR $(/ / 00,000)$ & 1,709 & 1,570 & 1,848 & 808 & 1,642 & 1,122 & 749 & 691 & 2,087 & 1,155 & 1,284 \\
\hline
\end{tabular}

are currently in place in this center to combat maternal death is not effective enough to reach the goal of improving MMR by 2015. The higher maternal mortality in Sokoto can be explained by the relatively lower socioeconomic status of women, cultural/religious beliefs, and poorer antenatal attendance. This results in type 1 delay, which is a delay in recognizing and reacting to problems relating to pregnancy and childbirth. In some instances, the pregnant woman needs to wait for her husband to provide money and permission before action can be carried out.

It is also of note that the MMR is lower in Ibadan and Lagos; this may be due to higher levels of education and availability of many qualified health professionals in western Nigeria, which is in sharp contrast with what happens in northern Nigeria. In western Nigeria, women have high levels of education and independence, and there are good communication systems and road networks, and many government and privately owned health facilities. These invariably reduce the three types of delay, which are the delay in recognizing and reacting (type 1), delay in reaching a health facility (type 2), and delay in receiving medical assistance (type 3).

Analyzing MMR trends over the 10 years under review, there was a steady decline over 2008, 2009, and 2010; this may have been due to the provision of 24-hour blood bank services; employment of more doctors; the creation of an independent obstetric anesthetic unit; the introduction of daily audit reviews of all obstetric and gynecological cases managed the previous day by all

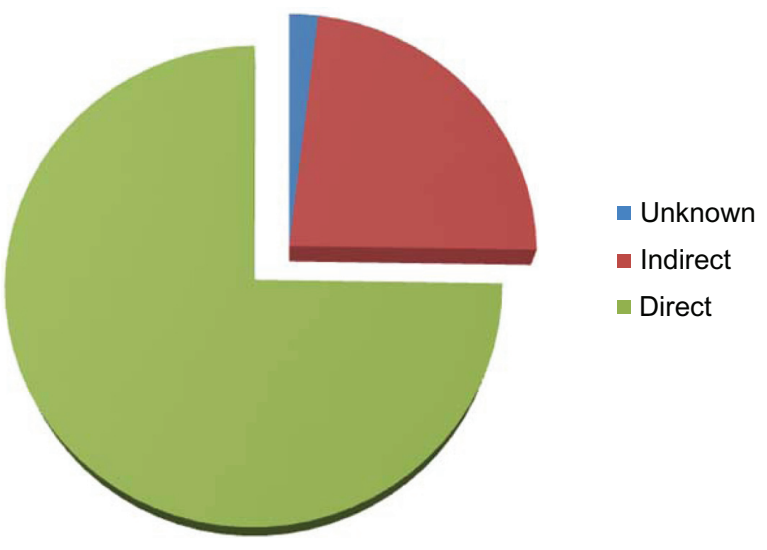

Figure I Medical causes of maternal death. residents, consultants in the department, and representatives of hospital management; sleep-in provision for the senior registrar and the consultant on call; stopping registrars from performing cesarean sections (all being performed by either the senior registrars or the on-call labor ward consultants); and provision of emergency care services to the patients in the first 48 hours without the requirement for immediate payment. During audit reviews, all challenges encountered that might have caused a type 3 delay in rendering of clinical services the previous day are taken care of. But in 2011, the MMR increased again, possibly due to increased confidence in the maternity homes within the catchment area of this center developed for the hospital, and referral of more patients, which possibly overwhelmed the system. Another reason could be that there were some levels of complacency in the system. This calls for upgrading of the system, especially regarding increased workforce numbers as demand rises to avoid the system being overstretched.

In this 10-year review (2003-2012), it is notable that the MMR in 2003 was 1,709/100,000 live births, while at the end of the tenth year (2012), it was reduced to 1,115/100,000 live births - a reduction of $24.86 \%$ over 10 years. This equates to a $2.486 \%$ reduction per year, instead of the required $5 \%$ per year to achieve MDG-5 in 15 years. At this rate, only a 37.29\% reduction will be achieved in 15 years, meaning it will take 30 years instead of 15 to achieve MDG-5; ie, MDG-5 will be achieved in 2030 rather than 2015. This means that NAUTH may be 15 years behind the rest of the world in achieving MDG-5 if nothing is done to improve the current situation. This goal can, however, be achieved by vigorously sustaining audit reviews and identifying type 3 delays on a daily basis and correcting them early. The provision of 24-hour blood bank services and an independent obstetric anesthetic unit are of great value. Increasing the workforce when necessary is also a very important measures toward achieving this goal. Research should be encouraged, possibly prospective studies, in intervals to study maternal mortality, its causes, and the effective or inefficient measures put in place to reduce it.

The direct causes of maternal mortality contributed $74.75 \%$ of maternal deaths, while indirect causes contributed $23.3 \%$ in this study. This represents what is obtainable in developing countries, where direct causes are the major 


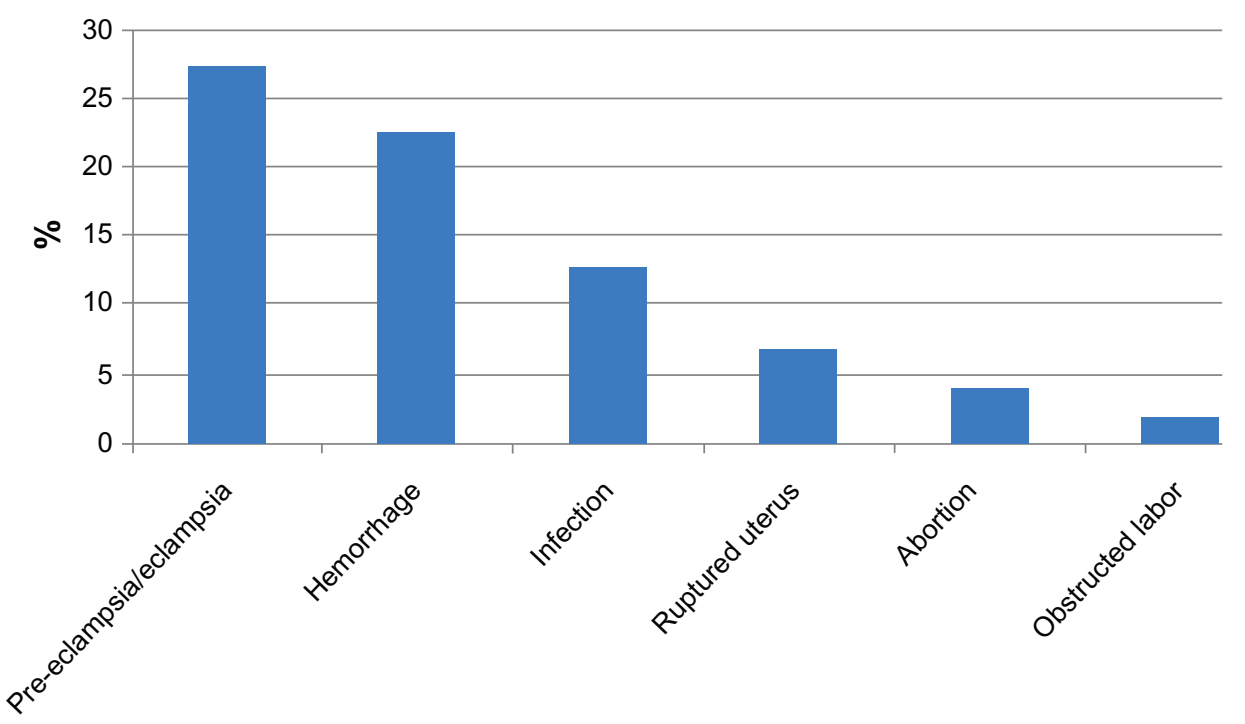

Figure 2 Direct medical causes of maternal death.

factors in maternal deaths, while indirect causes are the leading factors in developed countries. ${ }^{12}$ This finding is in contrast to the previous study in this center, in which indirect causes contributed $64 \%$ of maternal mortality. ${ }^{11}$

The major causes of maternal mortality were pre-eclampsia (27\%), hemorrhage $(22 \%)$, and sepsis $(12 \%)$. All of these are preventable causes of maternal death. The contribution of pre-eclampsia to maternal death is on the increase, and it contributes to more maternal deaths than hemorrhages, as observed in other recent studies in Nigeria, ${ }^{10,11}$ although some studies in Nigeria have found that hemorrhage is still the leading cause of maternal mortality. ${ }^{12-14}$ The finding that pre-eclampsia contributes more than hemorrhage to maternal death may be explained by the availability of functional blood bank services and use of oxytocic drugs in our hospital, which help to reduce the contribution of hemorrhage to maternal death. Therefore, the functional blood bank service and use of oxytocic drugs should be sustained. Despite the use of magnesium sulfate in the management of pre-eclampsia in this center, the MMR was still very high; this may be due to the fact that most of the patients were not booked, and tend to present to the hospital when it is too late to save them. If they were booked, raised blood pressure and protein in urine could have been detected earlier and appropriate action taken to arrest the situation. This suggests the need for increased awareness about the importance of antenatal care services,

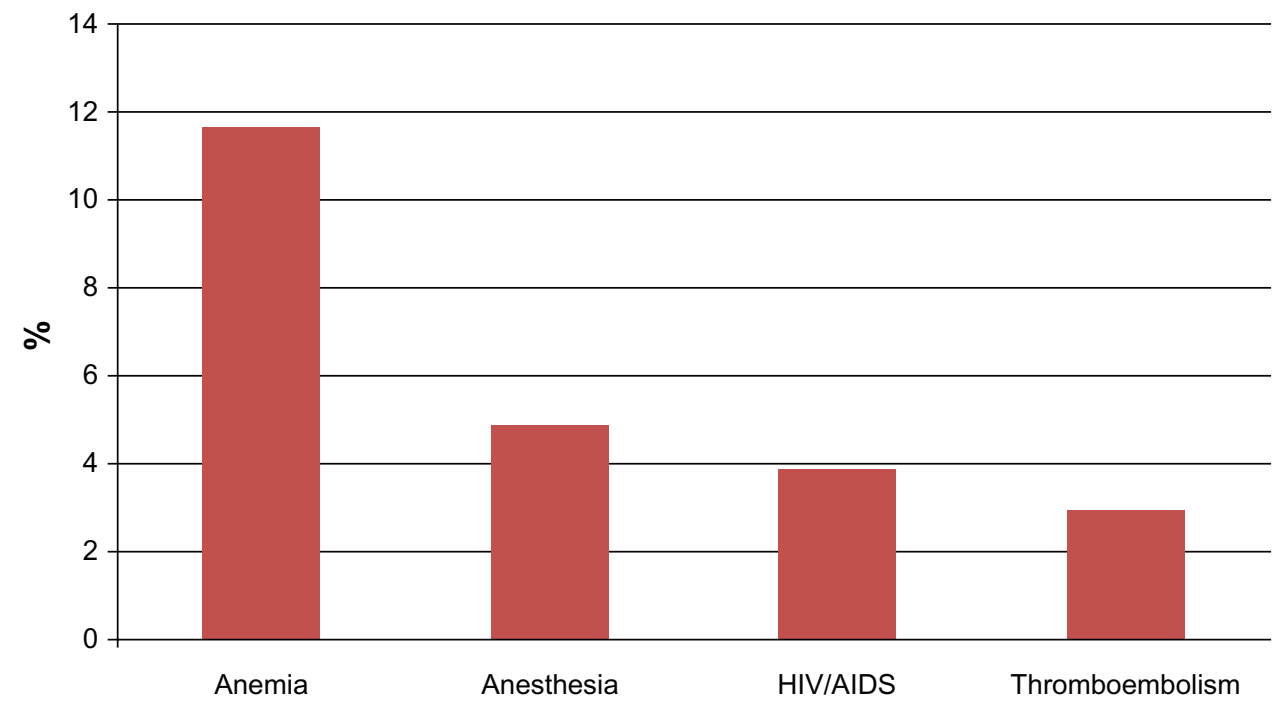

Figure 3 Indirect medical causes of maternal death. 
where pre-eclampsia could be detected and treated before the stage of eclampsia, which has a high mortality rate, is reached. Furthermore, the peripheral health facilities that refer patients should be educated on the need for early referral, rather than referral when the patient is moribund and saving their life is near impossible.

The major indirect medical causes of maternal death were anemia, anesthesia, and HIV encephalopathy. There is a need to improve on both the hemoglobin status (which can be done when they are booked for antenatal care) and socioeconomic (which is a remote cause of maternal death) status of our women. Anesthetic-related deaths can be reduced in number by training/retraining our anesthetic doctors in order to keep up to date with the newest and safest techniques available, especially epidural in pre-eclampsia/eclampsia cases. There is a need for preventive counseling and testing for HIV in pregnancy; those detected to be HIV-positive should be placed on highly active antiretroviral therapy, as this will help reduce HIV encephalopathy among our women.

It is notable that, in this study, unbooked patients constituted about $98 \%$ while booked patients accounted for only $2 \%$ of maternal mortalities. This is in keeping with previous studies, in this center ${ }^{15}$ and in a neighboring center. ${ }^{16}$ Some patients in Nigeria utilize traditional birth attendants, maternity homes, and spiritual houses for deliveries. ${ }^{17}$ This is because the community believes that maternal death is due to punishment from the gods as a result of antisocial activities (adultery) of the woman, hence does not require orthodox medications. Even in instances when they decide to seek medical assistance, women are often hampered by poor communication and transport systems and badly maintained roads; as such, they may only present to hospital in a moribund state, when any intervention would produce little or no result. ${ }^{18}$ The inability to recognize or react to risks or reach the medical facilities and delays in referral may be other causes of the high maternal mortality in Southeast Nigeria. There is a need for both governmental and nongovernmental organizations to aid in creation of awareness and abolition of laws that militate against safe motherhood, as well as in the provision of effective communication and road networks and accessible, affordable, and functional health care.

It was found that most of the deaths $(75.73 \%)$ in our study occurred within 48 hours of admission; hence, there is a need for urgent, aggressive, and close monitoring of our patients during the first 48 hours, which may require the involvement of the labor consultant in the management of high-risk patients in the first 48 hours of presentation to the hospital, when crucial decisions on the management of the patient must be made. This period also requires intensive monitoring and care of the patient.

To increase the chances of achieving MDG-5 earlier than 2030, as predicted by this study, all hands must be on deck - women, men, the community, and governmental and nongovernmental organizations must all get involved. The socioeconomic status of the populace should be improved upon, along with women's independence, creation of awareness, and political determination, with the aim of encouraging pregnant women to book for antenatal care, where the pregnancy will be monitored and abnormalities can be detected and corrected. Availability, accessibility, and affordability of emergency care services to pregnant women are of utmost importance, irrespective of class, tribe, creed, and socioeconomic conditions.

\section{Conclusion}

Unless something is done to improve on the present situation, it will take NAUTH until 2030 to achieve MDG-5. The major causes of maternal mortality are preventable. Suggested measures to reduce maternal mortality include: universal education and women's independence; availability, accessibility, and affordability of antenatal services; and 24-hour emergency obstetric services. Partnership among the community, health workers, and governmental and nongovernmental organizations should be encouraged. The roles of political determination and further research cannot be overemphasized in the aim of reducing the MMR in this tertiary health institution in Southeast Nigeria.

\section{Disclosure}

The authors report no conflicts of interest in this work. The authors alone are responsible for the contents and writing of the paper. The study was conducted in the course of service in the hospital and no funding was received from any source.

\section{References}

1. Aboyeji AP, Ijaiya MA, Fawole AA. Maternal mortality in a Nigerian teaching hospital - a continuing tragedy. Trop Doct. 2007;37:83-85.

2. Society of Gynaecology and Obstetrics of Nigeria (SOGON). Policy Handbook and Strategic Plan on Women's Health (2000-2010). Benin City: Ambik Press.

3. Ojo OA, Savage VY. A ten year review of maternal mortality in the University College Hospital, Ibadan, Nigeria. Am J Obstet Gynecol. 1974;118:517-522.

4. Olutunji AD, Abudu OO. A review of maternal mortality in Lagos University Teaching Hospital. Nigerian Medical Practitioner. 1996;31: 2-6

5. Ngwan SD, Swende TZ. Maternal mortality in JOS Nigeria: a facility based prospective review. International Journal of Biological and Medical Research. 2011;2(2):565-568.

6. FMOH. National Demographic health survey (NDHS) Abuja, Nigeria 2008:1-50 
7. Ashworth MF. Harare Hospital maternal mortality report for 1987 and comparison with previous reports. Cent Afr J Med. 1994;36:209-212.

8. Carol B. The state of the world's children 2004 UNICEF. 2005: $130-132$.

9. Uzoigwe SA, John CT. Maternal mortality in university of Port-Harcourt Teaching Hospital in the last year before the new millennium. Niger $J$ Med. 2004;13(1):32-35.

10. Audu LR, Ekele BA. A ten year review of maternal mortality in Sokoto, northern Nigeria. West Afr J Med. 2002;21(1):74-76.

11. Ukanwa U, Obiechina NJA, Ezebialu I. Contribution of indirect Obstetric death to maternal mortality at Nnamdi Azikiwe University teaching Hospital, Nnewi. Tropical Journal of Medical Research. 2009;13: 55-57.

12. Fubara DS, Ikimalo J, John CT. Pathology of maternal deaths in Rivers state (a ten year autopsy review) in a referral hospital. Niger Postgrad Med J. 2007;14(3):256-260.

13. Aboyeji AP. Trends in maternal mortality in Ilorin, Nigeria. Trop $J$ Obstet Gynaecol. 1998;15(1):15-20.
14. Mutihir TJ, Golit WN. A review of policies and programs for promoting maternal health in Plateau state, Nigeria. Afr J Reprod Health. 2010;14(3):43-48.

15. Obiechina NJA, Okonkwo JEN, Obi RA. Maternal mortality at Nnamdi Azikiwe University Teaching Hospital, Nnewi, Nigeria: an eight year survey. Tropical Journal of Medical Research. 2000;4(2):1-5.

16. Obiechina NJA, Udegbe CB. Maternal mortality at St Charles Borromeo Hospital, Onitsha: a six year review. Orient Journal of Medicine. 2003;15(3\&4):26-30.

17. Okpere EE. Maternal mortality in Nigeria. In: Okpere EE, editor. Clinical Obstetrics. Revised edition. Uniben Press, University of Benin, Benin City, Nigeria;2003:389-397.

18. Agan Tu, Archibong EI, Ekabua JE, et al. Trends in maternal mortality at the University of Calabar Teaching Hospital, Nigeria, 1999-2009. Int $J$ Womens Health. 2010;2:249-254.
International Journal of Women's Health

\section{Publish your work in this journal}

The International Journal of Women's Health is an international, peerreviewed open-access journal publishing original research, reports, editorials, reviews and commentaries on all aspects of women's healthcare including gynecology, obstetrics, and breast cancer. The manuscript management system is completely online and includes

\section{Dovepress}

a very quick and fair peer-review system, which is all easy to use. Visit http://www.dovepress.com/testimonials.php to read real quotes from published authors. 